\title{
Osteomalacia and Hyperparathyroid Bone Disease in Patients with Nephrotic Syndrome
}

\author{
Hartmut H. Malluche, David A. Goldstein, and Shaul G. Massry, \\ Division of Nephrology and Department of Medicine, University of Southern \\ California, School of Medicine, Los Angeles, California 90033
}

A B S T R A C T Patients with nephrotic syndrome have low blood levels of 25 hydroxyvitamin D (25-OH-D) most probably because of losses in urine, and a vitamin D-deficient state may ensue. The biological consequences of this phenomenon on target organs of vitamin $\mathrm{D}$ are not known. This study evaluates one of these target organs, the bone. Because renal failure is associated with bone disease, we studied six patients with nephrotic syndrome and normal renal function. The glomerular filtration rate was $113 \pm 2.1$ (SE) $\mathrm{ml} / \mathrm{min}$; serum albumin, $2.3 \pm 27 \mathrm{~g} / \mathrm{dl}$; and proteinuria ranged between 3.5 and $14.7 \mathrm{~g} / 24 \mathrm{~h}$. Blood levels of $25-\mathrm{OH}-\mathrm{D}$, total and ionized calcium and carboxy-terminal fragment of immunoreactive parathyroid hormone were measured, and morphometric analysis of bone histology was made in iliac crest biopsies obtained after double tetracycline labeling. Blood 25-OH-D was low in all patients $(3.2-5.1 \mathrm{ng} / \mathrm{ml}$; normal, $21.8 \pm 2.3 \mathrm{ng} / \mathrm{ml})$. Blood levels of both total $(8.1 \pm 0.12 \mathrm{mg} / \mathrm{dl})$ and ionized $(3.8 \pm 0.21 \mathrm{mg} / \mathrm{dl})$ calcium were lower than normal and three patients had true hypocalcemia. Blood immunoreactive parathyroid hormone levels were elevated in all. Volumetric density of osteoid was significantly increased in three out of six patients and the fraction of mineralizing osteoid seams was decreased in all. Evidence for an increase in active lacunae (bone-osteoclast interface) occurred in three out of six patients and in inactive (Howship's lacunae) bone resorption in six out of six. The data indicate that the loss of 25-OH-D in urine of patients with nephrotic syndrome and normal renal function may result in a decrease of blood levels of ionized calcium, secondary hyperparathyroidism and enhanced bone resorption. In addition, the vitamin D-deficient state causes osteomalacia as evidenced by defective mineralization and increased osteoid volume.

Dr. Goldstein is a recipient of a Fellowship from the National Institutes of Health No. 1F32 AM 05754.

Received for publication $10 \mathrm{July} 1978$ and in revised form 30 October 1978.

\section{INTRODUCTION}

Disturbances in calcium homeostasis are not infrequent in patients with nephrotic syndrome. These include hypocalcemia (1-4), hypocalciuria $(1,2,4)$, and impaired intestinal absorption of calcium $(1,2)$. The mechanisms underlying these derangements are not evident. Because most patients with nephrotic syndrome also have renal failure, the latter may play a role in the abnormalities of calcium metabolism in these patients.

Recently, Goldstein et al. (5), Schmidt-Gayk et al. (6), and Barragry et al. (7) reported that patients with nephrotic syndrome have very low levels of 25hydroxyvitamin D (25-OH-D) ${ }^{1}$ most probably because of losses of this metabolite in urine. Goldstein et al. (5) found that patients with nephrotic syndrome and normal renal function have low blood concentrations of ionized calcium and modest elevations in the blood level of parathyroid hormone (PTH). They suggested that a state of vitamin D deficiency exists in these patients and may underlie the derangements in calcium homeostasis (5).

However, data on the biological consequences of the deficiency of 25-OH-D on target organs in patients with nephrotic syndrome and normal renal function are not available. This study was undertaken to evaluate bone histology in six nephrotic patients with normal renal function.

\section{METHODS}

The clinical and laboratory data of the six patients are given in Table I. All patients were female, and their ages ranged from 19 to 27 yr. There were five whites and one black. They all were ambulatory and presumably had similar sun exposure because they were studied during the same 4 mo period of June through August. The diagnosis of the nephrotic syndrome was made by hypoalbuminemia, proteinuria $(>3.5$

${ }^{1}$ Abbreviations used in this paper: 25-OH-D, hydroxyvitamin D; PTH, parathyroid hormone; iPTH, immunoreactive $\mathrm{PTH}$. 
TABLE I

Laboratory Data in Patients with Nephrotic Syndrome and Normal Kidney Function

\begin{tabular}{|c|c|c|c|c|c|c|c|c|c|c|c|c|}
\hline Patient & Sex & Age & $\mathrm{Cr}$ & ${ }^{\mathrm{c}} \mathrm{Cr}$ & $\begin{array}{c}\text { Protein } \\
\text { excretion }\end{array}$ & $\begin{array}{c}\text { Serum } \\
\text { albumin }\end{array}$ & 25-OH-D & $\mathrm{Ca}$ & $\mathrm{Ca}_{\mathrm{a}_{1}}$ & iPTH & $\mathrm{P}$ & $\mathrm{Mg}$ \\
\hline & & & $\mathrm{mg} / 100 \mathrm{ml}$ & $\mathrm{ml} / \mathrm{min}-1.73 \mathrm{~m}^{2}$ & $g / 24 h$ & $\mathrm{~g} / 100 \mathrm{ml}$ & $n g / m l$ & $\mathrm{mg} / \mathrm{l} 00 \mathrm{ml}$ & $m g / 100 \mathrm{ml}$ & pleq/min & $\mathrm{mg} / \mathrm{l}(00 \mathrm{ml}$ & $\mathrm{mg} / \mathrm{loO} \mathrm{ml}$ \\
\hline 1 & $\mathbf{F}$ & 27 & 0.83 & 91 & 6.3 & 2.4 & 4.3 & 8.3 & 4.18 & 40 & 4.8 & 1.86 \\
\hline 2 & $\mathrm{~F}$ & 21 & 0.70 & 99 & 14.7 & 1.9 & 3.7 & 7.88 & 4.12 & 30 & 4.7 & 2.54 \\
\hline 3 & $\mathrm{~F}$ & 19 & 0.90 & 168 & 10.4 & 1.1 & 5.1 & 7.96 & 3.52 & 75 & 4.1 & 1.78 \\
\hline 4 & $\mathrm{~F}$ & 23 & 0.73 & 103 & 7.1 & 2.7 & 4.4 & 7.74 & 3.71 & 63 & 3.3 & 2.07 \\
\hline 5 & $\mathrm{~F}$ & 19 & 0.60 & 95 & 3.5 & 3.0 & 4.3 & 8.54 & 4.34 & 35 & 3.0 & 1.83 \\
\hline 6 & $\mathrm{~F}$ & 26 & 1.00 & 126 & 14.5 & 2.4 & 3.2 & 7.88 & 2.92 & 85 & 3.6 & 1.81 \\
\hline
\end{tabular}

Abbreviations used in this table: $\mathrm{Cr}$, creatinine; ${ }^{\mathrm{C}} \mathrm{Cr}$, creatinine clearance; $\mathrm{Ca}_{1}$, ionized calcium; $\mathrm{ND}$, not detectable.

g/d), lipiduria, and edema. Etiology of the nephrotic syndrome was diabetes mellitus in one, focal sclerosis in three, focal glomerulonephritis in one, and membranoproliferative glomerulonephritis in one. The diagnosis of the renal disease in the last five patients was made by renal biopsy. All had normal renal function as evidenced by normal blood levels of creatinine and normal values of glomerular filtration rate. Marked proteinuria of $3.5-14.7 \mathrm{~g} / \mathrm{d}$ was present in all patients for at least 1 mo duration. This may be an underestimation, because the nephrotic syndrome might have been present for a longer period of time before the patient showed overt clinical manifestations. The patients did not have other illnesses nor did they receive steroid therapy or any other medications known to affect bone metabolism. They ingested diets containing $800-1,000 \mathrm{mg}$ of calcium, $800-1,000 \mathrm{mg}$ of inorganic phosphorus, and $2 \mathrm{~g}$ of sodium.

Iliac crest bone biopsies were obtained after oral tetracycline double labeling (8). The drug $(1,000 \mathrm{mg} / \mathrm{d})$ was given orally for $2 \mathrm{~d}$, followed by $12 \mathrm{~d}$ without tetracycline administration; thereafter, the drug was readministered for another $4 \mathrm{~d}$. $2 \mathrm{~d}$ later, bone biopsy was performed in an operating room under local anesthesia using an electric drill (Straumann Inc., Waldenburg, Switzerland); intravenous diazepam was given as needed during the drilling procedure. Two bone samples, $2-3 \mathrm{~cm}$ apart, were obtained to take into account intrinsic histological variability. Informed consent was obtained from all patients.

The bone samples were first coded and then embedded in methylmethacrylate and undecalcified sections of $3 \mu \mathrm{m}$ thickness were obtained with a Jung microtome model 1140 (Jung Inc., Heidelberg, Germany). The sections were stained using a trichrome stain according to Masson-Goldner (9) which allows differentiation of calcified from uncalcified bone. The stained sections were evaluated with a Zeiss photomicroscope III. Micromorphometric measurements were done with an integrating grid as described by Merz and Schenck (10). In the evaluation of the sections, 250 fields at $\times 200$ were counted. Several sections from the two bone samples were evaluated and the mean values for the various parameters were calculated. Unstained sections of $7 \mu \mathrm{m}$ thickness were evaluated under fluorescent light to assess tetracycline uptake. The mean distance between two fluorescent bands as well as the mean width of diffusely labeled osteoid seams of at least 50 formation sites were measured and appositional rates were calculated. The results were compared with normal values from 20 normal age-matched (range, 18-29; mean, $23 \pm 2.8$ yr) Californian subjects; these bone biopsies were obtained at autopsy from trauma victims within $9 \mathrm{~h}$ of death. Again two bone samples from different sites were used for the morphometric analysis. The normal values for mineralizing osteoid (tetracycline uptake) are ob- tained from studies in Germany on paid healthy volunteers, because we could not obtain information on tetracycline labeling of osteoid in normal American subjects.

The blood levels of 25-OH-D were measured by competitive protein-binding assay (11). The blood levels of immunoreactive $\mathrm{PTH}$ (iPTH) were determined by radioimmunoassay with sheep antisera 478 (kindly supplied by Dr. C. Arnaud, University of California, Veterans Administration Hospital, San Francisco), ${ }^{125}$ I-bovine PTH, and pooled sera from patients with renal failure as a standard. This assay recognizes predominantly carboxy-terminal fragments of PTH. The normal value for the assay in our laboratory is up to $20 \mu \mathrm{leq} / \mathrm{ml}$. The blood levels of total calcium were measured by Perkin-Elmer atomic absorption photometer (model 503; Perkin-Elmer Corp., Instrument Div., Norwalk, Conn.) and of ionized calcium with an Orion flow-thru electrode (model SS20; Orion Research Inc., Cambridge, Mass.). Creatinine and inorganic phosphorus were determined by Technicon AutoAnalyzer (Technicon Instruments Corp., Tarrytown, N. Y.)

\section{RESULTS}

The blood levels of total and ionized calcium, iPTH, 25-OH-D, and micromorphometric parameters of bone histology are given in Tables I and II. The concentra-

TABLE II

Histomorphometric Parameters of Bone Formation and Mineralization

\begin{tabular}{ccccc}
\hline Patient & ${ }^{r}$ min & "double & "diffuse & "total \\
\hline & $\%$ & $\mu m / d$ & $\mu \mathrm{m} / d$ & $\mu \mathrm{m} / d$ \\
1 & 48 & 0.5 & 0.6 & 0.6 \\
2 & 48 & 0.6 & 0.7 & 0.7 \\
3 & 46 & 0.8 & 0.9 & 0.9 \\
4 & 30 & 0.6 & 1.2 & 1.0 \\
5 & 37 & 0.5 & 0.7 & 0.7 \\
6 & 41 & 0.6 & 1.0 & 0.9
\end{tabular}

Normal $>60$

$1.1 \pm 0.45$

Abbreviations used in this table: ${ }^{\mathrm{F}} \mathrm{min}$, fraction of mineralizing osteoid seams, indicating fraction of osteoid seams with tetracycline double label. "double, appositional rate of bone formation sites with double tetracycline uptake. "diffuse, appositional rate of bone formation sites with diffuse tetracycline uptake. "total, appositional rate of total bone formation sites. 


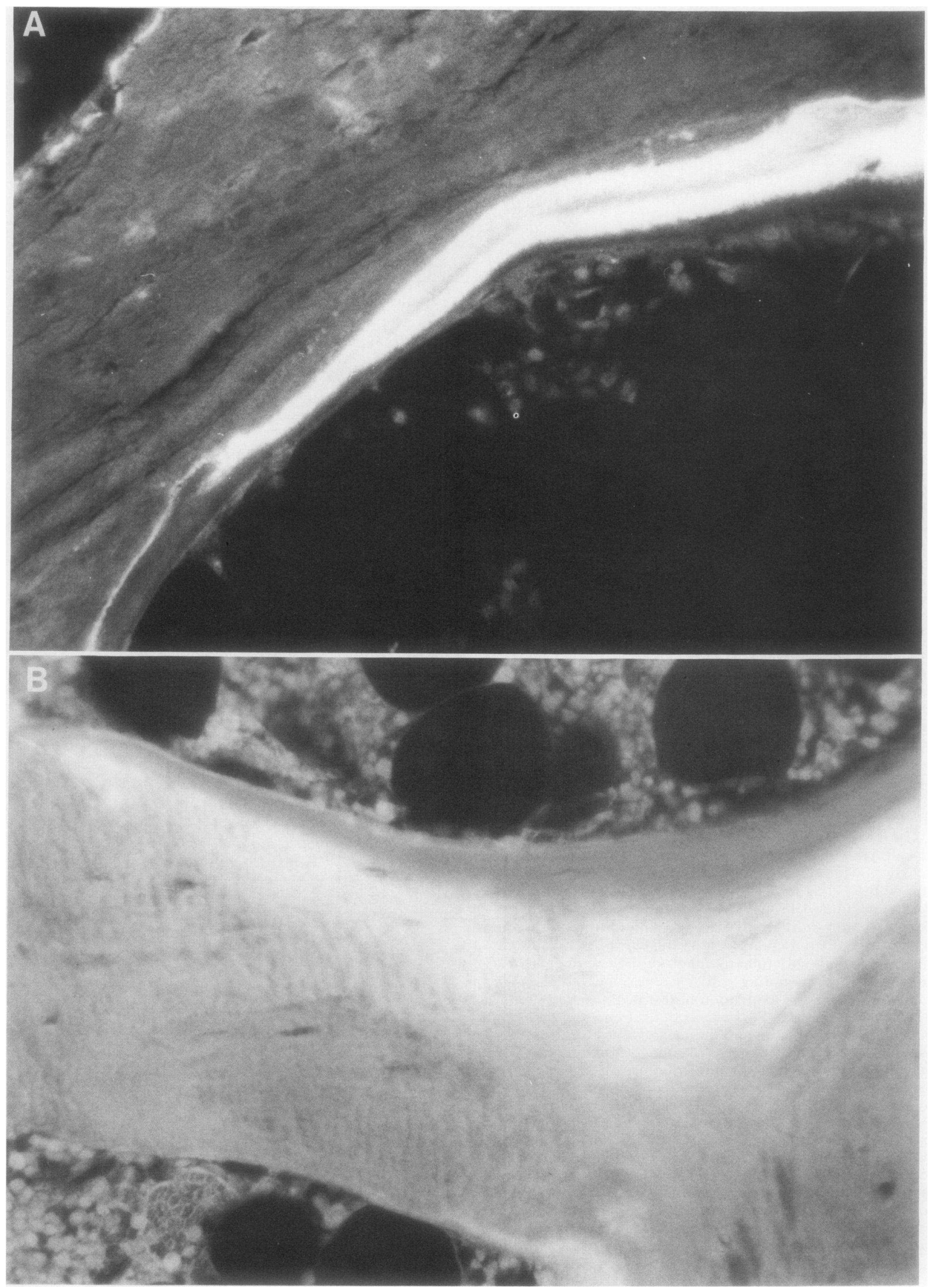


tions of total calcium in blood were low and ranged between 7.74 and $8.54 \mathrm{mg} / 100 \mathrm{ml}$ and the levels of ionized calcium were low in three patients (Nos. 3, 4, and 6) (normal values, $3.95-4.50 \mathrm{mg} / 100 \mathrm{ml}$ ). All patients had low levels of 25-OH-D ranging between 3.7 and 5.1 $\mathrm{ng} / \mathrm{ml}$ (normal value, $21.8 \pm 2.3[\mathrm{SE}] \mathrm{ng} / \mathrm{ml}$ ). The blood levels of iPTH were elevated and ranged from 30 to 85 $(54.7 \pm 9.3[\mathrm{SE}] \mu \mathrm{leq} / \mathrm{ml})$.

The results of micromorphometric analysis of bone are given in Tables II and III. The most remarkable finding in bone histology was a marked decrease in the fraction of mineralizing osteoid seams, i.e., decrease in osteoid seams exhibiting the typical double bands of tetracycline uptake (Fig. 1, Table II). Normally, $>60 \%$ of the entire osteoid seams are actively mineralizing (12); in our patients only $30-48 \%$ of the osteoid seams displayed a normal pattern of mineralization.

Total appositional rate ranged between 0.6 and 1.0 $\mu \mathrm{m} / \mathrm{d}$. The appositional rate of formation sites with double or diffuse uptake of tetracycline were similar in four patients (Nos. 1-4). Appositional rate of bone formation sites with diffuse tetracycline uptake was higher than the appositional rate of bone formation sites with double tetracycline uptake in two patients (Nos. 4 and 6). Also, an increase in volumetric density of osteoid was observed in three of six patients. The fraction of trabecular surface covered by unmineralized osteoid seams was increased in patients 3 and 4 . Woven osteoid was not found in any of the patients.

All six patients displayed an increase in the fraction of mineralized trabecular surface covered by Howship's lacunae (Fig. 2, Table III). The surface density of bone osteoclast interface (active lacunae) was increased only in patients 3,4 , and 6 , and the bone changes characteristic of hyperparathyroidism were most pronounced in patient 6 . Patients 1,2 , and 5 had increased total lacunae but without evidence for current enhanced bone resorption.

\section{DISCUSSION}

The results of this study demonstrate that in patients with nephrotic syndrome and normal renal function, the low blood levels of 25-OH-D are associated with histological abnormalities of bone consistent with vitamin D deficiency. The patients displayed a histological picture of osteomalacia as documented by disturbed mineralization of osteoid seams and increased volumetric density of osteoid (12). The former abnormality is evidenced by the diffuse uptake of tetracycline by osteoid seams (Fig. 1). However, the lack of double uptake of tetracycline may occur under other circumstances. First, marked suppression of the rate of new bone formation may result in merging of the two tetracycline bands giving the misleading appearance of diffuse uptake (12). Our data on appositional rate vitiate this possibility. An appositional rate of $0.5 \mu \mathrm{m} / \mathrm{d}$ permitted us to discriminate double bands of tetracycline uptake (Table II). None of the appositional rates of the diffusely labeled formation sites were $<0.5 \mu \mathrm{m}$. It seems, therefore, that diffuse tetracycline uptake in our patients could not be attributed to merging tetracycline bands. Second, hyperparathyroidism may be associated with diffuse tetracycline uptake because of rapid bone formation resulting in the appearance of woven osteoid (8). This is an unlikely explanation for the diffuse uptake in our patients, because bone formation was not enhanced and woven osteoid was not present in any of them. It appears, therefore, that the diffuse uptake of tetracycline in our patients is a result of defective mineralization.

The presence of an increase in the fraction of mineralized surfaces covered with Howship's lacunae can be accounted for by two mechanisms. First, bone has been, or is being, exposed to excess PTH $(13,14)$ and second, lacunae produced by regular bone reabsorption are not filled by normally mineralizing osteoid because of vitamin $\mathrm{D}$ deficiency. Only three patients who had the higher blood levels of iPTH displayed evidence of enhanced current bone resorption. The other three patients with mild elevation in blood levels of iPTH had no evidence of increased active lacunae but had increased total number of lacunae, suggesting a delayed filling of previously resorbed lacunae.

Available data (5-7) provide evidence that there is a loss of 25-OH-D in the urine of nephrotic patients. This results in a deficient state of 25-OH-D. However, a deficiency of other vitamin $\mathrm{D}$ metabolites such as $1,25(\mathrm{OH})_{2} \mathrm{D}_{3}$ and $24,25(\mathrm{OH})_{2} \mathrm{D}_{3}$ may also exist in such patients. If these latter metabolites are also bound to a serum protein which may be lost in the urine of patients with nephrotic syndrome, their blood levels may fall as well. Adequate data on this issue are not available. In addition, despite normal renal function, a low substrate (25-OH-D) state may cause a decrease in the production of $1,25(\mathrm{OH})_{2} \mathrm{D}_{3}$ and(or) $24,25(\mathrm{OH})_{2} \mathrm{D}_{3}$. Jubiz et al. (15) reported that in patients treated with anticonvulsant medications, the blood levels of $1,25(\mathrm{OH})_{2} \mathrm{D}_{3}$ were normal despite low levels of 25 $(\mathrm{OH})_{2} \mathrm{D}_{3}$. However, the blood levels of 25-OH-D in our patients are $(4.2 \pm .26[\mathrm{SE}] \mathrm{ng} / \mathrm{ml})$ lower than in the patients of Jubiz et al. (15) $(7.9 \pm 1.02[\mathrm{SE}] \mathrm{ng} / \mathrm{ml})$, and we cannot, therefore, exclude the possibility that our patients had low blood levels of $1,25(\mathrm{OH})_{2} \mathrm{D}_{3}$ as well. Whether patients with nephrotic syndrome have a pure 


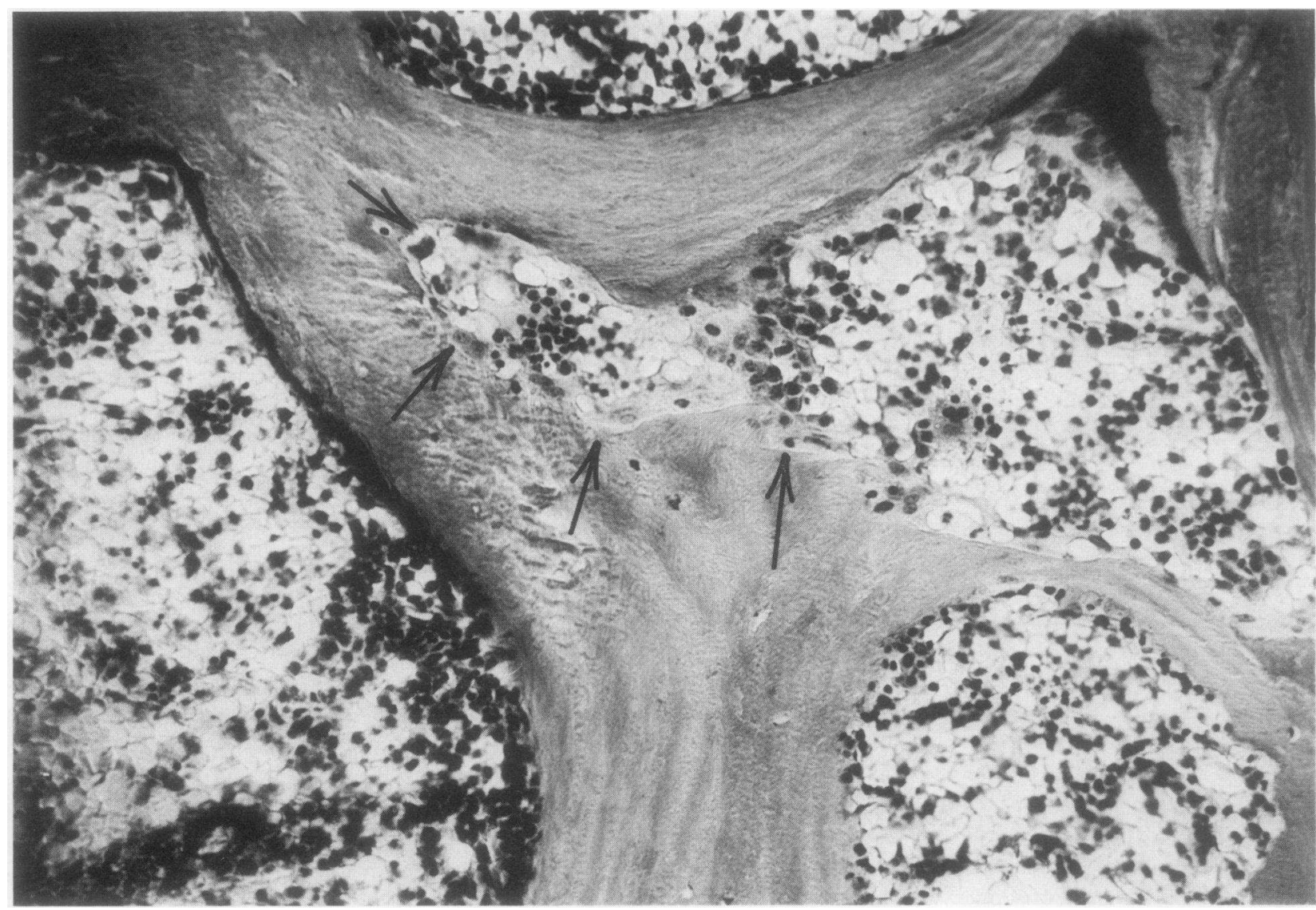

FIGURE 2 Photomicrograph $(\times 160)$ of undecalcified section $(3 \mu \mathrm{m})$ of iliac crest biopsy from patient 3 (Table II). The section was stained after Masson-Goldner. Note the accumulation of osteoid appearing as black areas in the right upper corner and on the left border of the trabeculum. Also, areas of bone resorption as shown by arrows are noted. In the center of the trabeculum a deep resorptive lacuna with osteoclasts lining part of its surface is seen.

deficiency of 25-OH-D or deficiency of other metabolites as well is not determined as yet.

Our data show that this vitamin D-deficient state in patients with nephrotic syndrome and normal renal function is associated with histological disturbance of bone. This could be produced through two pathways. First, a deficiency of 25-OH-D produces defective mineralization of newly formed bone matrix and, hence, osteomalacia. Second, a fall in the blood levels of ionized calcium secondary to vitamin $\mathrm{D}$ deficiency stimulates the activity of parathyroid glands and causes secondary hyperparathyroidism which, in turn, induces enhanced bone resorption.

It is interesting that all patients had defective mineralization, whereas evidence for increased osteoid volume or enhanced bone resorption occurred only in some. This suggests that the first bone abnormality in patients with nephrotic syndrome is a disturbance in mineralization. Such a postulate is further supported by the finding in patients 1,2 , and 5 who had no evidence of current enhanced bone resorption and normal osteoid volume but unequivocal defective mineralization. The development of other abnormalities in bone is probably dependent on the duration and magnitude of the losses of 25-OH-D in the urine and the consequent changes in ionized calcium and parathyroid gland activity. We did not endeavor to evaluate a statistical correlation between histologic findings and blood levels of 25-OH-D because the values of the latter were uniformly and profoundly decreased. Variations in the micromorphometric parameters among our patients might have been a result of the duration of the 25-OH-D-deficient state.

Indirect evidence for disturbance in bone metabolism in patients with nephrotic syndrome has been reported. Emerson and Beckman (2) found generalized rarefaction of the diaphysis in children with nephrotic syndrome. Gottfried et al. (16) reported that some of their nephrotic children had radiographic evidence of bone demineralization. Similar observations were 
TABLE III

Micromorphometric Results in Nephrotic Patients with Normal Renal Function

\begin{tabular}{crrrrrr}
\hline Patient & \multicolumn{1}{c}{$\mathrm{V}_{\mathrm{v}}$} & \multicolumn{1}{c}{$\mathrm{V}_{\mathrm{vos}}$} & \multicolumn{1}{c}{$\mathrm{S} / \mathrm{V}$} & \multicolumn{1}{c}{$\mathrm{OS}$} & \multicolumn{1}{c}{$\mathrm{SV}_{\text {inc }}$} & $\mathrm{HL}$ \\
\hline & \multicolumn{1}{c}{$\%$} & $\%$ & $\mathrm{~mm}^{2} / \mathrm{mm}^{3}$ & \multicolumn{1}{c}{$\%$} & $\mathrm{~mm}^{2} / \mathrm{mm}^{3}$ & $\%$ \\
1 & 16.1 & 0.53 & 21.7 & 4.2 & 10.40 & 19.9 \\
2 & 24.4 & 0.39 & 21.9 & 2.8 & 15.60 & 22.7 \\
3 & 30.9 & 4.67 & 15.5 & 22.3 & 36.40 & 20.2 \\
4 & 24.1 & 2.34 & 15.6 & 21.9 & 36.40 & 31.5 \\
5 & 24.9 & 0.31 & 20.6 & 9.3 & 5.20 & 15.3 \\
6 & 22.2 & 1.06 & 21.0 & 15.8 & 62.41 & 23.9 \\
Normal mean \pm 2 SD & 22.1 & 0.58 & 20.8 & 9.2 & 20.3 & 6.5 \\
& \pm 12.2 & \pm 0.29 & \pm 8.2 & \pm 10.9 & \pm 14.4 & \pm 7.2 \\
\hline
\end{tabular}

Abbreviations used in this table: HL, fraction of Howship's lacunae, indicating the fraction of mineralized (nonosteoid) trabecular surface covered by resorption lacunae (active and inactive); OS, fraction of osteoid seams, representing the fraction of trabecular surface covered by osteoid seams; $S / \mathrm{V}$, specific surface, i.e., the ratio of trabecular surface to trabecular volume; this ratio falls as trabecular diameter rises; $\mathrm{SV}_{\mathrm{OCl}}$, surface density of bone-osteoclast interface (active osteoclastic lacunae); $V_{v}$, volumetric density of bone (indicating the fraction of spongiosal volume occupied by bone matrix); $V_{\text {vos }}$, volumetric density of osteoid (indicating the fraction of spongiosal volume occupied by osteoid).

noted by Jones et al. (4) in adults. These findings were interpreted as osteoporosis. However, Jones et al. (4) found that nephrotic patients retained $84 \pm 3.8 \%$ of an infused calcium load as compared to $27-55 \%$ (mean, $41 \%$ ) in normal subjects (17). This finding is consistent with the presence of osteomalacia in patients with nephrotic syndrome.

Data on bone histology in patients with nephrotic syndrome and renal failure are not available. It is possible that the losses of 25-OH-D in such patients may worsen bone disease and alter the various components of renal osteodystrophy.

\section{ACKNOWLEDGMENTS}

We are thankful for the technical assistance of Ms. Susan Barragan and the secretarial assistance of Ms. Melinda Ayers, Ms. Gracy Fick, Mrs. Jamie Jimenez, and Mrs. Alice Moomjean.

\section{REFERENCES}

1. Scriver, W. de M. 1928. Observations on the excretion of calcium in two cases of nephrosis treated with parathyroid extract. J. Clin. Invest. 6: 115-125.

2. Emerson, K., and W. W. Beckman. 1945. Calcium metabolism in nephrosis. I. A description of an abnormality in calcium metabolism in children with nephrosis. $J$. Clin. Invest. 24: 564-572.

3. Hooft, C., A. Vermassen, and M. Van Belle. 1960. On calcaemia and phosphataemia in the nephrotic syndrome. Comparative study of the periods before and after the introduction of hormone therapy. Helv. Paediatr. Acta. 15: 437-450.

4. Jones, J. H., D. K. Peter, and D. B. Morgan. 1967. Observations on calcium metabolism in the nephrotic syndrome. Q. J. Med. 36: 301-320.
5. Goldstein, D. A., Y. Oda, K. Kurokawa, and S. G. Massry. 1977. Blood levels of 25-hydroxyvitamin D in nephrotic syndrome. Studies in 26 patients. Ann. Intern Med. 87: 664-668.

6. Schmidt-Gayk, H., W. Schmitt, C. Grawunder, E. Ritz, W. Tschoepe, V. Pietsch, K. Andrassy, and R. Bouillon. 1977. 25-hydroxy-vitamin-D in nephrotic syndrome. Lancet. II: 105-108.

7. Barragry, J. M., M. W. France, N. D. Carter, J. A. Auton, M. Beer, B. J. Boucher, and R. D. Cohen. 1977. Vitamin-D metabolism in nephrotic syndrome. Lancet. II: $626-629$.

8. Malluche, H. H., E. Ritz, and H. P. Lange. 1976. Bone histology in incipient and advanced renal failure. Kidney Int. 9: 355-362.

9. Schenk, P. K. 1965. Zur histologischen Verarbeitung von unetkalkten Knochen. Acta Anat. 60: 3-19.

10. Merz, W. H., and R. K. Schenk. 1970. Quantitative structural analysis of human cancellous bone. Acta Anat. 75: $54-66$.

11. Haddad, J. G., and T. C. B. Stamp. 1974. Circulating 25-hydroxyvitamin D in man. Am. J. Med. 57: 57-62.

12. Ritz, E., H. H. Malluche, B. Krempien, and O. Mehls. 1977. Bone histology in renal insufficiency. In Calcium Metabolism in Renal Failure and Nephrolithiasis. D. S. David, editor. John Wiley \& Sons, Inc., New York. 197-235.

13. Malluche, H. H., E. Ritz, J. Kutschera, G. Krause, E. Werner, A. Gati, U. Seiffert, and H. P. Lange. 1975. Calcium metabolism and impaired mineralization in various stages of renal insufficiency. In Vitamin D and Problems Related to Uremic Bone Disease. A. W. Norman, K. Schaefer, H. G. Grigoleit, D. Herrath, E. Ritz, editors. Gruyter \& Co., Berlin. 513-523.

14. Bordier, P. J., C. Arnaud, C. Hawker, S. Tun Chot, and D. Hioco. 1973. Relationship between serum immunoreactive parathyroid hormone, osteoclastic and osteocytic bone resorptions and serum calcium in primary hyperparathyroidism and osteomalacia. In Clinical Aspects of 
Metabolic Bone Disease. B. Frame, A. M. Parfitt, H. Duncan, editors. Excerpta Medica, Amsterdam. 222-229.

15. Jubiz, W., M. R. Haussler, T. A. McCain, and K. G. Tolman. 1977. Plasma 1,25-Dihydroxyvitamin D levels in patients receiving anticonvulsant drugs. J. Clin. Endocrinol. Metab. 44: 617-621.
16. Gottfried, S. P., J. F. Steinman, and B. Kramer. 1947. Chemical studies in children with the nephrotic syndrome. Am. J. Dis. Child. 74: 283-304.

17. Nordin, B., and D. Fraser. 1956. A calcium infusion test. I. Urinary excretion data for recognition of osteomalacia. Lancet. I: 823-826. 